\title{
CARACTERIZAÇÃO FÍSICO-QUÍMICA DE PROGÊNIES DE MARACUJÁ-ROXO E MARACUJÁ-AZEDO CULTIVADOS NO DISTRITO FEDERAL ${ }^{1}$
}

\author{
SIDNEY ALMEIDA FILGUEIRADE MEDEIROS², OSVALDO KIYOSHI YAMANISHI ${ }^{3}$, \\ JOSÉ RICARDO PEIXOTO ${ }^{4}$, MÁRCIO CARVALHO PIRES ${ }^{5}$, NILTONTADEU VILELAJUNQUEIRA ${ }^{6}$, \\ JULIANAGALVARROS BUENOLOBORIBEIRO
}

RESUMO - A qualidade de frutos de maracujá para o consumo in natura é um fator de extrema importância na comercialização para o mercado europeu. Diante disso, um experimento foi realizado com o objetivo de avaliar as características físico-químicas de frutos de maracujazeiro nas condições de cerrado. Utilizou-se um delineamento de blocos casualizados, com nove tratamentos e quatro repetições. Os tratamentos constaram de sete progênies de maracujá-roxo provenientes da Austrália e duas progênies de maracujáazedo. As progênies de maracujazeiro-roxo utilizadas foram: 'Lacey’, ‘14’, ‘25', 'Supersweet 9', ‘37(1)’, '37(2)’ e ‘96A’ e os de maracujazeiro-azedo foram 'Marília Seleção Cerrado’ e ‘Híbrido EC-2-0’. Com base nos resultados, pode-se concluir que o genótipo ‘37(2)’ apresentou o maior teor de sólidos solúveis totais, a progênie ‘Lacey’ apresentou a menor espessura de casca e formato mais arredondado dos frutos, a progênie ‘Marília Seleção Cerrado’ obteve o maior peso de polpa e o maior número de sementes por fruto. Entre as progênies de maracujá-roxo, o maior peso da polpa foi da progênie 'S9', que também apresentou maior pH e menor acidez titulável. A cor da polpa predominante foi amarela. A correlação entre peso da polpa e acidez titulável mostrou-se positivamente forte, e a correlação entre pH e acidez titulável foi negativamente forte. Termos para indexação: Passiflora edulis Sims, características físico-químicas, exportação.

\section{PHYSICO-CHEMICAL CHARACTERISTICS OF PURPLE AND ACID-PASSION-FRUIT GENOTYPES GROWN IN BRASÍLIA}

\begin{abstract}
Fruit quality for fresh passion fruit is a key factor for commercialization in European market. Aiming to evaluate the physico-chemical characteristics of passion fruits grown under Savanna condition an experiment was carried out using a randomized design with nine treatments and four replications. The treatments consisted of nine cultivars and selections (seven purple- and two acid-passion-fruit). The purplegenotypes ('Lacey', '14', '25', 'Supersweet 9', '37(1)', '37(2)’ and '96A' ) are from Australia and the yellowones ('Marília Seleção Cerrado’ and ‘Híbrido EC-2-0’) from Brasília, Brazil. The selection ‘32(2)’ showed the highest content of TSS; 'Lacey' the thinnest peel and a more round fruit shape; and 'Marília Seleção Cerrado’ the largest number of seeds per fruit and the heaviest pulp weight. Among the purple-genotypes selection, 'S9' showed the heaviest pulp weight, the highest $\mathrm{pH}$ and the lowest TA. The Yellow pulp color was predominant. Positive correlation for pulp weight and TA and inversely for $\mathrm{pH}$ and TA were observed. Index Terms: Passiflora edulis Sims, physico-chemical characteristics, export.
\end{abstract}

\footnotetext{
1(Trabalho 154-08). Recebido em: 13-06-2008. Aceito para publicação em: 14-01-2009.

${ }^{2}$ Eng. Agr. MsC. Faculdade de Agronomia e Medicina Veterinária, Universidade de Brasília. sidneymedeiros@unb.br ${ }^{3}$ Eng. Agr. Dr. Faculdade de Agronomia e Medicina Veterinária, Universidade de Brasília. kiyoshi@unb.br ${ }^{4}$ Eng. Agr. Dr. Faculdade de Agronomia e Medicina Veterinária, Universidade de Brasília. peixoto@unb.br ${ }^{5}$ Eng. Agr. MsC. Faculdade de Agronomia e Medicina Veterinária, Universidade de Brasília. mcpires@unb.br ${ }^{6}$ Eng. Agr. Dr. Embrapa Cerrados - Brasília/DF. junqueir@cpac.embrapa.br

${ }^{7}$ Eng. Agr. Faculdade de Agronomia e Medicina Veterinária, Universidade de Brasília. julianagalvarros@brturbo.com.br
} 


\section{INTRODUÇÃO}

Os atributos de qualidade dos produtos dizem respeito a sua aparência, sabor, aroma, textura, valor nutritivo e segurança (Chitarra, 1994). Para Chitarra \& Chitarra (1990), a aparência é o fator de qualidade mais importante na determinação do valor de comercialização do produto. O consumidor brasileiro mostra nítida preferência pelos frutos com formato ovalado. Já no mercado externo, a preferência do consumidor é por frutos de formato arredondado (Salomão et al., 2001). Chavan \& Kadam (1995), analisando a composição nutricional de maracujás amarelos e roxos, concluíram que o maracujá-roxo possui maior teor de ácido ascórbico do que o maracujá-amarelo. São José (1994) considera desejável que o fruto apresente mais de 33\% de suco, acima de $15 \%$ de sólidos solúveis, coloração alaranjado-intensa do suco, massa acima de $200 \mathrm{~g}$ e formato ovalado. Segundo Ruggiero et al. (1996), o maracujá-amarelo disponível no mercado tem apresentado entre 50 e 130 g de peso, máximo de 36\% de rendimento de suco e sólidos solúveis totais entre 13 e $18^{\circ}$ Brix. O maracujá-amarelo apresenta dimensões maiores e a polpa mais ácida e não tão aromática quanto à do roxo (Menzel \& Simpson, 1994 e Pruthi, 1963).

Kwok et al. (1974), avaliando frutos cultivados no Havaí, encontraram valores de $\mathrm{pH}$ da ordem de 2,8 em maracujá-amarelo e 4,2 em maracujároxo, comprovando a maior acidez do maracujáamarelo. Esta acidez elevada do maracujá-amarelo possui importância industrial, pois permite maior flexibilidade na adição de açúcar no preparo de bebidas prontas (Souza \& Sandi, 2001). Souza \& Sandi (2001) afirmam que a relação açúcares/acidez é normalmente mais elevada no maracujá-roxo do que no maracujá-amarelo, o que torna o sabor do maracujá-roxo mais adocicado e, por isso, mais aceito em países europeus, para ser consumido in natura. A fruta mais ácida (maracujá-azedo) é usada para confecção de suco (industrializado ou doméstico), enquanto o maracujá é consumido pelos europeus como fruta fresca. O teor de sólidos solúveis da polpa pode variar entre $14 \%$ e $18 \%$, e a acidez entre 3 a 5\% de ácido cítrico.

Para a comercialização do maracujá no mercado europeu, a fruta não deve apresentar manchas nem estar danificada. Em geral, o peso deve estar entre 45 e 59g, e o diâmetro entre 45 e 50mm (Durigan et al., 2004). No Brasil, o Programa Brasileiro para a Melhoria dos Padrões Comerciais e Embalagens de Hortigranjeiros elaborou a Norma de Classificação, Padronização e Identidade do
Maracujá-Azedo, de adesão voluntária, mas que tem servido como norteador dos padrões para o maracujá comercializado no País (Ceagesp, 1997).

De acordo com reuniões informais junto a produtores de maracujá, a produtividade de maracujá-roxo no Brasil é baixa, em torno de $5 \mathrm{t} / \mathrm{ha} /$ ano. Entretanto, isto não representa uma limitação para seu cultivo, porque, para o maracujá-roxo, a qualidade dos frutos é mais importante que a produção quantitativa. Apesar de seus frutos serem bastante diferentes, pequenos e redondos, há que se considerar conjuntamente produção e as demais características. Ele representa a preferência do mercado internacional, pelo seu elevado teor de sólidos solúveis e baixa acidez, que dispensa o uso de açúcar quando consumido e eleva o rendimento industrial na agroindústria (Toda Fruta, 2002).

Critérios de qualidade:

\section{Características físicas}

- Cor da casca: é o atributo de qualidade mais atrativo para o consumidor (Chitarra, 1994). As mudanças de coloração durante o amadurecimento são correlacionadas, por estes consumidores, com o aumento da “doçura” e com o desenvolvimento de outros atributos desejáveis (Leão, 2001).

- Cor da polpa: avaliada por métodos subjetivos, onde são estabelecidos padrões de cor, baseados em intensidades e nuances perceptíveis ao olho humano (Chitarra, 1994).

-Tamanho do fruto: avaliado pelos seguintes parâmetros: circunferência, diâmetro, comprimento, largura, peso ou volume. Normalmente, os produtos para comercialização são classificados pelo comprimento, diâmetro e peso (Chitarra \& Chitarra, 1990).

- Número de sementes: a quantidade de sementes está diretamente relacionada com o teor de suco, porque a sarcotesta que envolve cada semente possui uma pequena quantidade desse líquido.

-Espessura da casca: visando ao aumento do espaço na câmara interna do fruto de maracujá (cavidade ovariana), o melhoramento genético de interesse deve apontar para o aumento do tamanho do fruto de maneira inversamente proporcional à espessura da casca (epicarpo e mesocarpo).

- Peso da polpa: o peso da polpa (sementes e sarcotesta) de maracujá relaciona-se com a densidade de cada fruto. Frutos do mesmo tamanho podem apresentar pesos diferentes devido à maior 
ou menor quantidade de polpa existente em seu interior.

\section{Características químicas}

-Acidez: a acidez total titulável (ATT) é uma importante característica de qualidade e é bastante variável em função tanto de fatores ambientais como de fatores da própria planta (cultivar, estágio de maturação, etc.) (Chitarra, 1997).

-Sólidos solúveis totais: indica a quantidade dos sólidos que se encontram dissolvidos no suco ou na polpa das frutas, sendo que os açúcares correspondem entre $65 \%$ e $85 \%$ do teor total desses sólidos. É normalmente expresso em ${ }^{\circ}$ Brix e tem tendência de aumento com a maturação (Chitarra \& Chitarra, 1990).

•pH: é variável de acordo com fatores ambientais e fatores da própria planta, mas é uma importante ferramenta para a avaliação da acidez dos frutos. Pelo valor do $\mathrm{pH}$, podem ser estabelecidos critérios de acidez de maneira comparativa entre os frutos.

O presente trabalho teve como objetivo avaliar a qualidade dos frutos de sete progênies de maracujá-roxo provenientes da Austrália e dois genótipos de maracujá-amarelo cultivados comercialmente no Brasil, por meio da análise de suas características físico-químicas.

\section{MATERIAL E MÉTODOS}

O experimento foi realizado no Setor de Fruticultura da Estação Experimental da Biologia EEB, Universidade de Brasília, situado no Distrito Federal, a uma latitude sul de $16^{\circ}$, longitude a oeste de Greenwich de $48^{\circ}$, e altitude de 1.010 metros acima do nível do mar. O clima da região é do tipo Aw, caracterizado por chuvas concentradas no verão, de outubro a abril e invernos secos, de maio a setembro (Melo, 1999). O delineamento experimental utilizado foi o de blocos casualizados, com 9 tratamentos, 7 plantas úteis por parcela e 4 repetições, numa área total de 0,25 hectare.

Testaram-se as seguintes progênies: a) 'Marília Seleção Cerrado' ('MSC'); b) ‘Híbrido EC2-0’; c) ‘Lacey’; d) ‘14’; e) ‘25’; f) ‘Supersweet 9'; g) '37(1)' - 'Misty Gem 37’ ou 'Supersweet 7’; h) ‘37(2)’ - 'Misty Gem 37' ou 'Supersweet 7'; i) '96A' ou 'Supersweet 4'. As progênies 'Marília Seleção Cerrado’ e 'EC-2-0’ são as mais cultivadas em larga escala na região Centro-Oeste do Brasil.

As nove progênies foram semeadas no dia 19-02-2004. As mudas foram produzidas em estufa, localizada na Estação Experimental da Biologia, em tubetes plásticos de $300 \mathrm{ml}$ cada, preenchidos com substrato artificial à base de vermiculita e casca de Pinus sp. Utilizaram-se 6 gramas de adubo NPK Osmocote $^{\circledR}$ (14-14-14) por litro de substrato.

O experimento foi instalado em um solo tipo Latossolo Vermelho, fase argilosa profundo, com boa drenagem e baixa fertilidade natural, apresentando as seguintes características: $\mathrm{Al}(0,1 \mathrm{mE} / 100 \mathrm{ml})$; $\mathrm{Ca}+\mathrm{Mg}(1,75 \mathrm{mE} / 100 \mathrm{ml}) ; \mathrm{P}(5,0 \mathrm{ppm}) ; \mathrm{K}(0,3 \mathrm{mE} / 100 \mathrm{ml})$; pH $(5,75)$; saturação de $\mathrm{Al}(5,5 \%)$; saturação de bases (33\%); e matéria orgânica (2,49\%). Foram aplicados 200 gramas de calcário dolomítico no fundo de cada cova, cujas dimensões eram de 40 x 40 x 40cm. Além disso, foram acrescentados $10 \mathrm{~kg}$ de esterco ovino curtido, 0,5kg de Yoorin Master ${ }^{\circledR}$ e 0,5kg de superfosfato simples por cova, incorporados ao solo. As mudas foram transplantadas para o campo no dia 05-06-2004, cento e sete dias após a semeadura. O espaçamento utilizado foi de 2,5 m entre linhas e 2,5m entre plantas, totalizando 1.600 plantas por hectare. As adubações de cobertura foram realizadas quinzenalmente, utilizando-se de $30 \mathrm{~g}$ de sulfato de amônio (20\% de N) e $10 \mathrm{~g}$ de cloreto de potássio (60\% de $\mathrm{K}_{2} \mathrm{O}$ ) por cova, até a formação da cortina pelas plantas; e $30 \mathrm{~g}$ de sulfato de amônio com $30 \mathrm{~g}$ de $\mathrm{KCl}$ por planta após esse período, visando à melhoria da produção. As adubações de coberturas foram realizadas a uma distância que variou de $30 \mathrm{~cm}$ a $50 \mathrm{~cm}$ do colo das plantas, à medida que as mesmas iam desenvolvendo-se. O plantio foi conduzido utilizando o sistema de sustentação em espaldeira vertical, com os mourões distanciados de $7 \mathrm{~m}$ e 1 fio de arame liso a 2,0 metros de altura em relação ao solo. As plantas foram conduzidas em haste única, tutoradas por barbante, até o fio de arame, deixando duas brotações laterais em sentido oposto uma da outra.

O controle de ervas daninhas foi realizado inicialmente com a pulverização de glifosato e, posteriormente, por meio de capinas manuais. Foi utilizada irrigação suplementar desde o plantio no campo até o início das chuvas em novembro de 2004. Foram realizadas pulverizações com um fungicida sistêmico (difenaconazol (triazol)), alternado com um fungicida preventivo (alquilenobis (ditiocarbamato)) + oxicloreto de cobre (inorgânico), em intervalos de 15 dias, durante todo o período de formação (crescimento vegetativo) até antes da primeira colheita, para controle de doenças.

As colheitas foram realizadas uma vez por semana, recolhendo somente os frutos que se encontravam no chão. As variedades de maracujazeiro-roxo australiano floresceram no mesmo período do maracujazeiro-azedo e não houve 
polinização manual. Os frutos colhidos eram levados para uma câmara fria e analisados posteriormente, anotando-se os resultados em uma planilha. A primeira colheita de frutos para análises físicoquímicas foi realizada no dia 01-02-2005, sendo a última no dia 29-03-2005, totalizando 09 colheitas ou, aproximadamente, 2 meses de produção. As variáveis físicas analisadas foram: número de sementes por fruto, espessura da casca, relação diâmetro equatorial/diâmetro polar, peso da polpa e cor da polpa; e as variáveis químicas analisadas foram: teor de sólidos solúveis totais, $\mathrm{pH}$ e acidez titulável.

Para a medição da espessura da casca, os frutos foram cortados ao meio, e a casca medida com o auxílio de um paquímetro digital; a relação entre o diâmetro equatorial e o diâmetro polar também foi calculada a partir da medição com o mesmo paquímetro. $\mathrm{O}$ peso da polpa foi obtido através da pesagem em balança eletrônica semianalítica, e a cor da polpa foi obtida através da comparação visual.

Na determinação do teor de sólidos solúveis totais (SST), foram colocadas gotas de suco no prisma do refratômetro manual, e, em seguida, foi realizada a leitura. Os resultados foram expressos em ${ }^{\circ}$ Brix. A determinação do $\mathrm{pH}$ foi realizada com a imersão do sensor do peagâmetro na polpa dos frutos cortados ao meio. Para calcular a acidez titulável (AT), que é expressa em porcentagem de ácido cítrico, utilizou-se a seguinte fórmula: onde:

$\%$ ácido cítrico $=(\mathrm{Vg} \times \mathrm{N} \times \mathrm{f} \times \mathrm{Eq}$. Ac. $) / 10$ x g,

$\mathrm{Vg}=$ volume de $\mathrm{NaOH}$ gasto $(\mathrm{ml})$;

$\mathrm{N}=$ normalidade da solução de $\mathrm{NaOH}$ utilizada $=0,1 \mathrm{~N}$;

$\mathrm{f}=$ fator de correção obtido para padronização do $\mathrm{NaOH}=1,00$;

Eq. Ac. = equivalente ácido, que para o maracujá é 64;

$\mathrm{g}=$ massa da amostra (1g).

\section{RESULTADOS E DISCUSSÃO}

A análise físico-química dos frutos de maracujá mostrou resultados diferentes nas duas épocas em que foi feita (Tabela 1). Entre fevereiro e março, as médias dos teores de sólidos solúveis totais, espessura da casca e de acidez titulável diminuíram de uma análise para a outra, todas com diferença significativa. Este fato pode estar atribuído às diferenças climáticas ocorridas na época. Apenas os valores de $\mathrm{pH}$ não diferiram significativamente, apesar de diminuírem entre as análises. A relação diâmetro equatorial/diâmetro polar também diminuiu com diferença significativa, ou seja, os frutos, no geral, apresentaram um formato mais alongado. Entretanto, o peso da polpa dos frutos foi maior na análise de março do que na de fevereiro.

Os teores de sólidos solúveis totais das progênies de maracujá-roxo superaram os valores das de maracujá-amarelo. A progênie 37(2) obteve o maior valor (15,57 $\left.{ }^{\circ} \mathrm{Brix}\right)$, a progênie de maracujáamarelo 'EC-2-0' obteve o menor valor de sólidos solúveis totais entre todas as progênies analisadas (13,27 ${ }^{\circ}$ Brix), diferindo significativamente de todas as progênies analisadas de maracujá-roxo. Para a variável espessura da casca, a progênie 'Lacey' foi a que apresentou o menor valor (3,68mm).

Fortaleza (2002) encontrou valores de espessura de casca que variaram entre 5,1 e 5,4 mm. Os valores de espessura da casca dos frutos de maracujá-roxo demonstram a capacidade que essas variedades têm em imprimir maior cavidade ovariana e, consequentemente, maior quantidade de polpa, proporcionalmente ao maracujá-amarelo. De acordo com Jagtiani (1988), Tocchini et al. (1994), Araújo et al. (1974), Kwok et al. (1974), Durigan et al. (2004) e Fortaleza (2002), os valores de sólidos solúveis totais para o maracujá-azedo encontram-se na faixa de 12,5 a $18,6^{\circ}$ Brix.

Os valores de peso da polpa das progênies de maracujá-azedo foram significativamente diferentes dos valores das progênies de maracujároxo. 'MSC' obteve o maior valor (81,35g), e entre as progênies de maracujá-roxo, os valores variaram de 29,23g ('S9’) a 20,47g (progênie 14). Os frutos de todas as progênies mostraram valores de relação diâmetro equatorial/diâmetro polar inferiores a 1, o que significa que todos tendem a ter um formato ovalado. Entretanto, as progênies 'Lacey' e '37(2)' são as que mais se aproximam do formato arredondado, já que o valor da relação é bastante próximo de 1.

O valor de $\mathrm{pH}$ da progênie ' $\mathrm{S9}$ ' $(3,44)$ foi o maior entre as progênies analisadas, obtivendo também melhor desempenho que as demais progênies quanto ao valor de acidez titulável, já que possui apenas $1,75 \%$ de ácido cítrico.

A acidez titulável das progênies de maracujáazedo foi maior do que todas as progênies de maracujá-roxo. Resultados parecidos foram encontrados por Menzel \& Simpson (1994) e Pruthi (1963), pois os mesmos afirmam que o maracujáazedo apresenta a polpa mais ácida do que o maracujá-roxo. Essa baixa acidez da polpa de maracujá-roxo é uma característica importante para fins de melhoramento genético do maracujazeiro (Nakasone \& Paull, 1999). Entretanto, Souza \& Sandi (2001) afirmam que a acidez elevada do maracujá- 
azedo possui importância industrial, já que garante maior flexibilidade na adição de açúcar em sucos.

Quanto ao número de sementes por fruto, as progênies 'MSC' (maracujá-azedo) e '25' (maracujároxo) obtiveram os melhores resultados, contandose 217,75 e 160,00 sementes por fruto em cada progênie, respectivamente (Tabela 2). De acordo com Durigan et al. (2004), o maracujá-azedo possui de 200 a 300 sementes em cada fruto. Porém, dos valores encontrados nas progênies de maracujá-azedo, apenas a progênie 'MSC' teve acima de 200 sementes por fruto. O baixo número de sementes por fruto pode ser explicado pelo fato de a contagem ter sido realizada na fase inicial de produção, quando o número de flores e de insetos polinizadores ainda era baixo.
De acordo com a Tabela 3, verifica-se que os valores de peso da polpa dos genótipos de maracujáazedo diferiram significativamente das progênies de maracujá-roxo nas duas épocas analisadas. Conforme a mesma Tabela, em todas as progênies analisadas, o peso da polpa aumentou de uma análise para a outra. Os valores de $\mathrm{pH}$ também variaram de uma época para a outra; entretanto, nesta variação, só houve diferença significativa entre as progênies de maracujá-azedo.

Dentre todas as progênies de maracujá analisados, a cor da polpa mais predominante foi a amarela (59,00\% dos frutos analisados), seguida da amarelo-clara (24,59\%), alaranjada (12,68\%) e avermelhada $(3,73 \%)$, todas com diferença significativa entre si. Essa característica tem importância industrial, já que desejável que o suco de maracujá-azedo possua coloração alaranjada da polpa (São José, 1994).

TABELA 1 - Teor de sólidos solúveis totais (SST), espessura da casca (EC), peso da polpa (PPolpa), relação diâmetro equatorial / diâmetro polar (ØEq/ØPol), pH e acidez titulável (AT) de maracujás amarelos e roxos analisados em duas épocas diferentes. Brasília-DF, EEB-UnB, 2005.

\begin{tabular}{llllllr}
\hline ÉPOCA & SST ( ${ }^{\circ}$ Brix) & $\begin{array}{l}\text { EC } \\
(\mathbf{m m})\end{array}$ & PPolpa(g) & ØEq/ØPol & $\mathbf{p H}$ & $\begin{array}{c}\text { AT } \\
(\% \text { ác. cítrico) }\end{array}$ \\
\hline $01-02$ a $21-02$ & $15,07 \mathrm{a}$ & $5,61^{\mathrm{a}}$ & $33,07 \mathrm{~b}$ & $0,96^{\mathrm{a}}$ & $3,17 \mathrm{a}$ & $2,84 \mathrm{a}$ \\
$01-03$ a $29-03$ & $14,51 \mathrm{~b}$ & $4,74 \mathrm{~b}$ & $40,39 \mathrm{a}$ & $0,93 \mathrm{~b}$ & $3,11 \mathrm{a}$ & $2,71 \mathrm{~b}$ \\
$\mathrm{CV}$ & $1,09 \%$ & $2,51 \%$ & $4,57 \%$ & $0,83 \%$ & $2,11 \%$ & $0,39 \%$ \\
\hline
\end{tabular}

Médias seguidas de mesma letra nas colunas não diferem significativamente entre si, a 5\%, pelo teste de Tukey.

TABELA 2 - Teor de sólidos solúveis totais (SST), espessura da casca (EC), peso da polpa (PPolpa), relação diâmetro equatorial / diâmetro polar (ØEq/ØPol), pH, acidez titulável (AT) e número de sementes por fruto (SMT) de dois genótipos de maracujá-amarelo e sete genótipos de maracujá-roxo. Brasília-DF, EEB-UnB, 2005.

\begin{tabular}{llllllll}
\hline \multirow{2}{*}{ GENÓTIPO } & $\begin{array}{c}\text { SST } \\
\left({ }^{\mathbf{0}} \mathbf{B r i x}\right)\end{array}$ & $\mathbf{E C}(\mathbf{m m})$ & $\mathbf{P P o l p a ( g )}$ & $\boldsymbol{\varnothing E q} / \boldsymbol{O P o l}$ & $\mathbf{p H}$ & $\begin{array}{c}\text { AT (\%) } \\
\text { ác. Cítrico }\end{array}$ & SMT \\
\hline MSC & $13,93 \mathrm{bc}$ & $6,60 \mathrm{ab}$ & $81,35 \mathrm{a}$ & $0,917 \mathrm{~b}$ & $2,74 \mathrm{~d}$ & $4,81 \mathrm{a}$ & $217,75 \mathrm{a}$ \\
EC-2-0 & $13,27 \mathrm{c}$ & $7,36 \mathrm{a}$ & $79,33 \mathrm{a}$ & $0,826 \mathrm{c}$ & $2,91 \mathrm{~cd}$ & $4,32 \mathrm{a}$ & $148,75 \mathrm{ab}$ \\
Lacey & $15,25 \mathrm{ab}$ & $3,68 \mathrm{e}$ & $22,33 \mathrm{~b}$ & $0,997 \mathrm{a}$ & $2,94 \mathrm{c}$ & $3,22 \mathrm{~b}$ & $105,00 \mathrm{~b}$ \\
14 & $15,07 \mathrm{ab}$ & $5,99 \mathrm{bc}$ & $20,47 \mathrm{~b}$ & $0,956 \mathrm{ab}$ & $3,23 \mathrm{~b}$ & $2,33 \mathrm{~cd}$ & $138,75 \mathrm{ab}$ \\
25 & $15,38 \mathrm{a}$ & $4,86 \mathrm{cde}$ & $24,27 \mathrm{~b}$ & $0,963 \mathrm{ab}$ & $3,19 \mathrm{~b}$ & $2,44 \mathrm{c}$ & $160,00 \mathrm{ab}$ \\
$\mathrm{S} 9$ & $14,79 \mathrm{ab}$ & $5,51 \mathrm{bcd}$ & $29,23 \mathrm{~b}$ & $0,965 \mathrm{ab}$ & $3,44 \mathrm{a}$ & $1,75 \mathrm{~d}$ & $139,75 \mathrm{ab}$ \\
$37(1)$ & $14,74 \mathrm{ab}$ & $4,09 \mathrm{e}$ & $24,37 \mathrm{~b}$ & $0,957 \mathrm{ab}$ & $3,34 \mathrm{ab}$ & $1,90 \mathrm{~cd}$ & $138,25 \mathrm{ab}$ \\
$37(2)$ & $15,57 \mathrm{a}$ & $4,13 \mathrm{e}$ & $25,07 \mathrm{~b}$ & $0,994 \mathrm{a}$ & $3,29 \mathrm{ab}$ & $1,87 \mathrm{~cd}$ & $132,25 \mathrm{ab}$ \\
$96^{\mathrm{a}}$ & $15,11 \mathrm{ab}$ & $4,35 \mathrm{de}$ & $24,14 \mathrm{~b}$ & $0,952 \mathrm{ab}$ & $3,19 \mathrm{~b}$ & $2,34 \mathrm{~cd}$ & $141,50 \mathrm{ab}$ \\
$\mathrm{CV}$ & $5,53 \%$ & $14,73 \%$ & $32,26 \%$ & $4,08 \%$ & $3,39 \%$ & $14,86 \%$ & $31,44 \%$ \\
\hline
\end{tabular}

Médias seguidas de mesma letra nas colunas não diferem significativamente entre si,a 5\%, pelo teste de Tukey. 
TABELA 3 - Interação entre a época de colheita e o peso da polpa de dois genótipos de maracujá-amarelo e sete genótipos de maracujá-roxo. Brasília-DF, EEB-UnB, 2005.

\begin{tabular}{|c|c|c|}
\hline \multirow{3}{*}{ Genótipo** } & \multicolumn{2}{|c|}{ Peso da Polpa (g) } \\
\hline & Época* & \\
\hline & 08/fev/2005 & $08 / \mathrm{mar} / 2005$ \\
\hline MSC & $70,56 \mathrm{~b} \mathrm{~A}$ & 92,14 a $\mathrm{A}$ \\
\hline EC-2-0 & $61,53 \mathrm{~b} \mathrm{~A}$ & 97,14 a A \\
\hline Lacey & 20,76 a $\mathrm{B}$ & 23,89 a $\mathrm{B}$ \\
\hline 14 & 19,96 a B & 20,99 a B \\
\hline 25 & 23,83 a $\mathrm{B}$ & 24,71 a B \\
\hline S9 & 28,95 a B & 29,50 a $B$ \\
\hline $37(1)$ & 23,15 a B & 25,59 a $\mathrm{B}$ \\
\hline $37(2)$ & 25,48 a B & 24,66 a B \\
\hline $96^{\mathrm{a}}$ & 23,38 a $\mathrm{B}$ & 24,91 a $B$ \\
\hline Coef. Variação A & $4,57 \%$ & \\
\hline Coef. Variação B & $32,26 \%$ & \\
\hline
\end{tabular}

*Avaliando época no sentido das linhas (letras minúsculas) - Médias seguidas de mesma letra nas linhas não diferem significativamente entre si, a 5\%, pelo teste de Tukey.

**Avaliando genótipo no sentido das colunas (letras maiúsculas) - Médias seguidas de mesma letra nas colunas não diferem significativamente entre si, a 5\%, pelo teste de Tukey.

TABELA 4 - Matriz de correlação linear para variáveis físico-químicas: teor de sólidos solúveis totais (SST), espessura da casca (EC), peso da polpa (PPolpa), relação diâmetro equatorial / diâmetro polar (ØEq/ØPol), pH e acidez titulável (AT). Brasília-DF, EEB-UnB, 2005.

\begin{tabular}{ccccccc}
\hline Variáveis & SST & EC & PPolpa & $\varnothing \mathrm{Eq} / \varnothing \mathrm{Pol}$ & $\mathrm{pH}$ & $\mathrm{AT}$ \\
\hline SST & - & $-0,405^{*}$ & $-0,643^{*}$ & $0,659^{*}$ & $0,365^{*}$ & $-0,487^{*}$ \\
EC & - & - & $0,558^{*}$ & $-0,442^{*}$ & $\begin{array}{c}0,295^{*} \\
*\end{array}$ & $0,515^{*}$ \\
& & - & & - & - & \\
PPolpa & - & - & - & $-0,702^{*}$ & $0,663^{*}$ & $0,718^{*}$ \\
ØEq/ØPol & - & - & - & - & $0,404^{*}$ & $-0,452^{*}$ \\
pH & - & - & - & - & - & $-0,792^{*}$ \\
AT & - & - & - & - & - & - \\
\hline
\end{tabular}

* Significativo ao nível de 1\% de probabilidade

**Significativo ao nível de $5 \%$ de probabilidade 


\section{CONCLUSÕES} concluir:

Com base nos resultados obtidos, pode-se

1-O teor de sólidos solúveis totais, espessura de casca, relação diâmetro equatorial/diâmetro polar e acidez titulável dos frutos de maracujazeiros analisados foram maiores no mês de fevereiro do que no mês de março, enquanto o peso de polpa foi no mês de março.

2-A progênie '37(2)' apresentou o maior teor de sólidos solúveis totais, enquanto a progênie “Marília Seleção Cerrado" apresentou o maior teor entre as progênies de maracujá-azedo.

3-A progênie 'Lacey' apresentou menor espessura da casca.

4-O pH foi maior nas progênies de maracujároxo do que nas variedades de maracujá-azedo.

5-Sete das nove progênies de maracujá analisadas apresentaram a polpa amarela como a cor predominante.

\section{REFERÊNCIAS}

ARAÚJO, C. M.; GAVA, A. J.; ROBBS, P. G.; NEVES, J. F.; MAIA, P. C. B. Características industriais do maracujá (Passiflora edulis var. flavicarpa) e maturação do fruto. Pesquisa Agropecuária Brasileira, Brasília, v.9, n.9, p.65-69, 1974.

CEAGESP. Boletim Anual. São Paulo: Secretaria de Agricultura e Abastecimento, 1997.

CHAVAN, U. D.; KADAM, S. S. Passion fruit. In: SALUNKHE, D. H.; KADAM, S. S. Handbook of fruit science and technology: production, composition, storage and processing. New York: Marcel Dekker, 1995. p.445-454.

CHITARRA, A. B. Qualidade, colheita e manuseio pós-colheita de frutos de pessegueiro e da ameixeira. Informe Agropecuário, Belo Horizonte, v.18, n.189, p.68-74, 1997.

CHITARRA, M. I. F.; CHITARRA, A. B. Pós-colheita de frutos e hortaliças: fisiologia e manuseio. Lavras: ESAL/FAEP, 1990. 320p.

CHITARRA, M. I. F. Colheita e qualidade póscolheita de frutos. Informe Agropecuário, Belo Horizonte, v.17, n. 179, p.08-18, 1994.
DURIGAN, J. F.; SIGRIST, J. M. M.; ALVES, R. E.; FILGUEIRAS, H. A. C.; VIEIRA, G. Qualidade e tecnologia pós-colheita do maracujá. In: LIMA, A. DE A.; CUNHA, M. A. P. da Maracujá: produção e qualidade na passicultura. Cruz das Almas: Embrapa Mandioca e Fruticultura, 2004. 396p.

FORTALEZA, J. M. Influência da adubação potássica e da época de colheita sobre as características físicoquímicas dos frutos de nove genótipos de maracujazeiro-azedo cultivados no Distrito Federal. 2002. 59 f. Dissertação (Mestrado) - Faculdade de Agronomia e Medicina Veterinária, Universidade de Brasília, Brasília, 2002.

JAGTIANI, J. (Ed.). Tropical fruit processing. San Diego: Academic Press, 1988. 194p.

KWOK, S.C.; CHAN JÚNIOR, H.T.; NAKAYAMA, T.O.M.; BREK-KE, J.E. Passion fruit starch and effect on juice viscosity. Journal of Food Science, Chicago, v.39, 1974. p.431-433.

LEÃO, R. Z. R. Qualidade dos frutos de mamoeiro (Carica papaya L.), cultivares Sunrise Solo e Tainung 1, produzidos nas regiões oeste e sul da Bahia. 2001. 99 f. Dissertação (Mestrado) Universidade de Brasília, Brasília, 2001.

MELO, K. T. Comportamento de seis cultivares de maracujazeiro-azedo (Passiflora edulis Sims e Passiflora edulis Sims f. flavicarpa Deg.) em Vargem Bonita, no Distrito Federal. 1999. 99 f . Dissertação (Mestrado) - Universidade de Brasília, 1999.99p.

MENZEL, C. M.; SIMPSON, D. R. Passionfruit. In: SCHAFFER, B.; ANDERSEN, P. C. (Ed.). Handbook of environmental physiology of fruit crops: subtropical and tropical crops. Boca Raton: CRC, 1994. v.2, p.225-241.

NAKASONE, H. Y.; PAULL, R. E. Tropical fruits. New York: CAB International, 1999. 445p. (Crop production science in horticulture series).

PRUTHI, J. S. Physical-chemical composition of passion fruit - Passiflora edulis Sims. The Indian Journal of Horticulture, Bangalore, v.15, n.2, p.8793, 1958.

PRUTHI, J. S. Physiology, chemistry and technology of passion fruit. Advances in food research, London, v.12, n.1, p.203-282, 1963. 
RUGGIERO. C.; SÃO JOSÉ, A. R.; VOLPE, C.; OLIVEIRA, J. C.; DURIGAN, J. F.; BAUMGARTNER, J. G.; SILVA, J. R. da; NAKAMURA, K.; FERREITA, M. E.; KAVATI, R.; PEREIRA, V. DE P. Maracujápara exportação: aspectos técnicos da produção. Brasília: Embrapa-SPI, 1996. 64p. (Publicações Técnicas Frupex, 19)

SALOMÃO, L. C. C.; VIEIRA, G.; MOTA, W. F. da. Tecnologia de colheita e pós-colheita. In: BRUCKNER, C.H.; PICANÇO, M.C. Maracujá: tecnologia de produção, pós-colheita, agroindústria, mercado. Porto Alegre: Cinco Continentes, 2001. 472p.

SÃO JOSÉ, A. R. A cultura do maracujazeiro: produção e mercado. Vitória da Conquista: DFZ/ UESB, 1994. 29p.
SOUZA, A. C. G. de; SANDI, D. Industrialização. In: BRUCKNER, C.H.; PICANÇO, M.C. Maracujá: tecnologia de produção, pós-colheita, agroindústria, mercado. Porto Alegre: Cinco Continentes, 2001. 472p.

TOCCHINI, R. P.; NISIDA, A. L. A. C.; HASHIZUME, T.; MEDINA, J. C.; TURATTI, J. N. Processamento: produtos, caracterização e utilização. In: ITAL. Maracujá: cultura, matéria-prima, processamento e aspectos econômicos. Campinas, 1994. p.161-196.

TODA FRUTA. Boletim eletrônico. Jaboticabal: SBF - Sociedade Brasileira Fruticultura. Edição on line de 28/02/2002. 4p. 